Journal of Bioinformatics and Computational Biology

(C) Imperial College Press

\title{
VALIDATION OF SIGNALLING PATHWAYS: CASE STUDY OF THE P16-MEDIATED PATHWAY
}

\author{
NIMET İLKE AKÇAY, RZA BASHIROV* \\ Department of Applied Mathematics and Computer Science \\ Eastern Mediterranean University \\ Famagusta, North Cyprus, via Mersin-10, Turkey \\ \{ilke.cetin,rza.bashirov\}@emu.edu.tr \\ ŞÜKRÜ TÜZMEN \\ Department of Biological Sciences \\ Eastern Mediterranean University \\ Famagusta, North Cyprus, via Mersin-10, Turkey \\ sukru.tuzmen@emu.edu.tr
}

Received (Day Month Year)

Revised (Day Month Year)

Accepted (Day Month Year)

\begin{abstract}
p16 is recognised as a tumor suppressor gene due to the prevalence of its genetic inactivation in all types of human cancers. Additionally, p16 gene plays a critical role in controlling aging, regulating cellular senescence, detection and maintenance of DNA damage. The molecular mechanism behind these events involves p16-mediated signalling pathway (or p16-Rb pathway), the focus of our study. Understanding functional dependence between dynamic behavior of biological components involved in the p16-mediated pathway and aforesaid molecular-level events might suggest possible implications in the diagnosis, prognosis and treatment of human cancer.

In the present work we employ reverse-engineering approach to construct the most detailed computational model of p16-mediated pathway in higher eukaryotes. We implement experimental data from the literature to validate the model, and under various assumptions predict the dynamic behavior of p16 and other biological components by interpreting the simulation results. The quantitative model of p16-mediated pathway is created in a systematic manner in terms of Petri net technologies.
\end{abstract}

Keywords: Signalling pathway; hybrid functional Petri net; quantitative modelling.

\section{Introduction}

Achievements in molecular biology and genetics over the past few decades have created a tremendous gap between accumulated biological data and their interpretation. Bringing together a posteriori knowledge with mathematical formalism

${ }^{*}$ Corresponding author. 
and tools of computer science provides an essential vehicle to close the existing gap. Computational modelling and simulation is a well-known approach to explore biological systems. The main idea behind this approach is to create the closest approximation of a biological system based on wet lab results, and predict its dynamic behavior through measuring the amounts of biological components. The success of this approach depends on success in all of its phases, which are the selection of appropriate modelling tool, gradual model development and its careful adjustment, model validation and prediction of dynamic behavior through simulation and analysis of simulation results. Researchers have come to realise that an appropriate modelling tool not only has to reproduce the biological system to desired outcome but also allow us to predict its behavior by interpreting the simulation results in a meaningful way. Nowadays, there exists a consensus among researchers that a quantitative description of dynamic behavior is all what we need to fully understand biological systems with complex interacting components.

In 2003, scientists with The Human Genome Project announced that they have identified approximately 20,000-25,000 genes on the human genome. These genes are spread out over 23 pair chromosomes. What we do know is that not all genes are equally important for survival of living organisms. Some genes are of critical importance, while others are of much less importance. The present research is focused on p16, a gene playing prominent role in controlling DNA damage, tumor suppression, replicative senescence and aging. p16 plays an important role in cell cycle regulation, particularly performing its functions by regulating p16-mediated signalling pathway. Inactivation of p16 leads to disruption of p16-mediated signalling pathway, a key cause of cancer in humans. This is the strongest argument to motivate further research in this area.

In the present research, we exploit hybrid functional Petri net (HFPN) as computational platform to create quantitative explanatory model of p16-mediated pathway describing the processes of the cell cycle regulation at G1 phase. We perform a series of simulations to validate the model for wild type p16 and its mutated form. Simulation results facilitate understanding the dynamic behavior of p16 in a normal functioning cell as opposed to a dysfunctional cell when DNA-damage or replicative senescence occurs.

The paper is organised as follows: we start with introducing the biological content to make it easy for the readers to understand the present research. Then the current related work in this field is reviewed. Next, we succinctly describe Petri nets, from its simplest form to HFPN. After that, we present our HFPN model of p16-mediated pathway, and draw a connection between model components and biological content. Following this, we discuss the simulation results, and we summarise our findings. 


\section{Biological context}

A cell is perhaps the smallest functional unit that exhibits all the characteristics of life. The cell cycle is an ordered and irreversible sequence of events that leads to cell division. The cell cycle events are classified into discrete periods or phases. These phases are aligned respectively in the order of G1 (gap period 1); S (synthesis); G2 (gap period 2); and M (mitosis). During G1 phase, based on information received from extracellular environment, cells decide whether to proliferate or not. It is in this phase cells start growing. DNA integrity is always under attack of environmental factors such as UV radiation and tabacco smoke. Damaged DNA is potential source for mutations and can lead to unregulated cell proliferation, a key cause of cancer. Intact or repaired DNA permits DNA replication which occurs in the S phase. G2 phase separates end of DNA synthesis from initiation of mitosis. Finally, M phase results in the production of two identical daughter cells from a single parent cell.

\subsection{Cyclins, cyclin dependent kinesis and inhibitors}

Advances in understanding of the cell cycle in the last two decades are tightly related with the discovery of cyclins and cyclin dependent kinesis (CDKs). CDKs as cell cycle regulators are not capable to perform their tasks alone. CDKs bind to associated cyclins to achieve their mission by promoting positive events and ensuring successful passage through the cell cycle transitions. Four classes of cyclins have been observed in a human cell, each centered around one Cyc/CDK complex. The CycD/CDK4-6 complex is responsible for progression in G1 phase, CycE/CDK2 complex regulates passage through $\mathrm{G} 1 / \mathrm{S}$ transition, CycA/CDK2 complex promotes the progression in $\mathrm{S}$ phase, and $\mathrm{CycB} / \mathrm{CDK} 1$ complex activity drives the G2/M transition.

Though Cyc/CDK complexes play a critical role in cell cycle regulation, there is another class of proteins that regulate these regulators; in human cells these are CDK inhibitors or CKIs, for short. Under certain circumstances CKIs bind to and inhibit the corresponding CDKs activity, preventing replication of DNA. Damaged DNA, cell cycle abnormality and environmental stresses are among circumstances that force CKIs to inhibit CDKs activity. CKIs are classified into two major families, INK4 and Cip/Kip. Four INK4 family proteins are p15, p16, p18 and p19. In contrast to INK4 proteins, Cip/Kip family proteins are more broadly acting inhibitors, whose actions affect the activities of cyclin D-, E-, and A-dependent kinases. The Cip/Kip family includes p21, p27 and p57. All of aforesaid inhibitors play fundamental role in tumor suppression. Inactivation of CKIs' tumor suppressing functions by gene mutations is one of the most frequent alterations found in human cancers.

\subsection{Cell cycle checkpoints and replicative senescence}

Failures in the DNA replication and environmental stresses such as UV radiation and tobacco smoke might cause DNA damage. Damaged DNA can result in loss of genetic information and mutations, destroying the control of cell proliferation. 
4 Nimet Ilke Akçay; Rza Bashirov; Şükrü Tüzmen

Cells use complex signaling pathways called the checkpoints to control the accuracy and consistency of cell division, detect and maintain DNA damage, and alleviate stresses on genomes. ${ }^{1}$ The checkpoints halt progression into the next phase of the cell cycle until damaged DNA has been precisely repaired. The most studied cell cycle checkpoints are transitions from G1 to S (G1/S checkpoint) and from G2 to M (G2/M checkpoint).

Human cells are not immortal as they undergo a finite number of cumulative population doublings, then enter a state termed replicative senescence. It was observed that normal human cells permanently can divide $50 \pm 10$ times (Hayflick limit) before they succumb to replicative senescence. ${ }^{3}$ In human cells, replicative senescence is a powerful tumour suppressive mechanism, which also contributes to ageing.

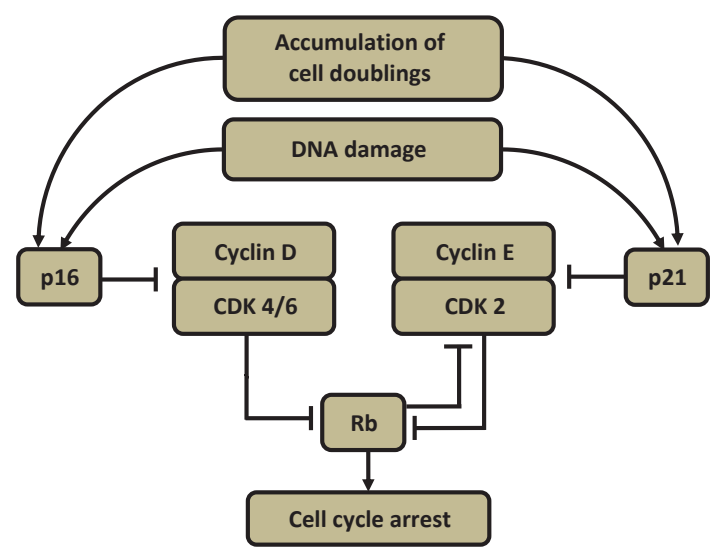

Fig. 1. Schematic illustration of p16- and p21-mediated control mechanism regulating DNA damage and replicative senescence.

\subsection{The p16-mediated and p21-Rb signalling pathways}

The tumor suppressor genes p16 and p21 play a key role in detection and repair of DNA damage and keeping track of replicative senescence. The p16 and p21 utilize their functions in G1 phase and G1/S checkpoint, respectively. Fig. 1 is a schematic illustration of p16- and p21-mediated control mechanism occurring in human cells. In wild-type human cells, CDK4 binds to CDK6, which in turn activates cyclin $\mathrm{D}$, and further inactivates $\mathrm{Rb}$ by phosphorylating it. Phosphorylation of $\mathrm{Rb}$ by CDK4/6 leads to activation of cyclin E, which in turn forms a complex with CDK2. A complex CycE/CDK2 further phosphorylates pRb. Phosphorylation of pRb by $\mathrm{CycE} / \mathrm{CDK} 2$ inactivates it and allows cells to enter $\mathrm{S}$ phase, resulting in the initiation of DNA replication. ${ }^{4,5}$ When number of accumulated cell doublings reaches the 
Hayflick limit ${ }^{3}$ p16 receives a signal on replicative senescence. As a result p16 binds to $\mathrm{CDK} 4 / 6$ inhibiting its activity thereby preventing Rb phosphorylation. ${ }^{6,7}$ This leads to irreversible arrest in G1 phase of cell cycle. When DNA damage is detected, the action of p16 again targets CDK4/6 and results in arrest in G1 phase until DNA damage is repaired. Inactivation of tumor suppressor gene p16 occurs through its mutation. Mutated p16 gene looses its gatekeeper role at G1 phase which might cause uncontrolled cell division leading to cancer. ${ }^{8}$ When p16 is mutated, p21 takes responsibility for controlling its functions in $\mathrm{G} 1 / \mathrm{S}$ checkpoint.

\section{Related work}

This section is a brief review of the mathematical and computational models of the cell cycle or its fragment based on the type of a cell being studied, and the method or tool being used to study.

Biologists distinguish between eukaryotic and prokaryotic cells. Eukaryotic cells contain a nuclei and organelles enclosed within membranes, while prokaryotic cells do not contain any nuclei. Nowadays, it is broadly-known that interactions between the key cell-cycle regulators are universal among eukaryotes. ${ }^{9}$ Modelling studies of Caulobacter crescentus bacterium, a single-celled prokaryote, have demonstrated that prokaryotic and eukaryotic cells follow the same outline though major components in eukaryotes are different from those in prokaryotes. ${ }^{10,11}$ In 1993 , it was predicted that CDK control system in eggs of the frog Xenopus laevis, which is a eukaryote, is bistable, meaning that the system is able to exist in two steady states. ${ }^{12}$ A decade later this prediction was proved experimentally. ${ }^{13,15}$ Many researchers have extensively modelled cell cycle of budding yeast Saccharomyces cerevisiae, a single-celled eukaryote, focusing on different aspects of cell cycle machinery. ${ }^{16-22}$ Some of their predictions regarding budding yeast were tested and proved experimentally. ${ }^{23}$ There exist models describing DNA replication, ${ }^{24,25}$ cell division, ${ }^{26}$ behavior of some mutants, ${ }^{27,28}$ and various aspects of cell regulatory systems ${ }^{29}$ for the fission yeast Schizosaccharomyces pombe, another single-celled eukaryote, as well as embryonic cell cycle of Drosophila melanogaster, ${ }^{30}$ and sea urchin. ${ }^{31}$ Interactions between complexes CycB-CDK1, Cdh1-APC, and monomers Cdc14 and Cdc20 expand macro-level understanding of cell cycle control. ${ }^{32}$ For detailed information the readers are referred to comprehensive reviews of existing models. ${ }^{33,34}$

The physiological variations among different types of eukaryotic cells make it challenging to model cell cycle of higher eukaryotes, though a number of attempts have been made to study cell cycle in higher eukaryotes. Modelling studies of basic proteins and their complexes in mammalian cell cycle have shown that in the presence of sufficient amount of growth factors, the system passes from stable steady state to sustained oscillations of cyclin/CDK complexes. ${ }^{35}$ Based on bifurcation analysis of mammalian cell cycle with feedback connections, some predictions have been made regarding bistability of G1/S transition. ${ }^{36}$ The relationship between phosphorylation and stability (or instability) of G1/S transition in mammalian cell 
cycle has also been analyzed. ${ }^{37}$ However, a model of cell cycle regulation in higher eukaryotes has not been constructed yet though there exist a number of case studies. ${ }^{19,33}$

Modelling of cell cycle or particular signalling pathway is usually performed by means of differential equations ${ }^{38}$ or in terms of continuous Petri nets. ${ }^{39}$ Both approaches are well-defined and have straightforward biological interpretation. As a major advantage, a Petri net-based approach is supported by a plenty of computational tools enabling visualization of models and simulation results. There exist many cell cycle models built in terms of ordinary differential equations, ${ }^{10-12,17,18,21,24-26,30,35,36}$ stochastic differential equations, ${ }^{28,40}$ stochastic Petri nets ${ }^{19}$ and HFPN. ${ }^{29,32}$

HFPNs have been extensively exploited for quantitative modelling and simulation of biological phenomena including switching mechanism of $\lambda$ phage ${ }^{41}$ circadian rhythms of Drosophila,${ }^{41}$ apoptosis signalling pathway, ${ }^{41}$ glycolytic pathway controlled by the lac operon gene, ${ }^{42}$ validation of transcriptional activity of the $\mathrm{p} 53,{ }^{43}$ antifolate inhibition of folate metabolism, ${ }^{44}$ cell fate specification during Caenorhabditis elegans vulval development, ${ }^{40}$ lac operon gene regulatory mechanism in the glycolytic pathway of Escherichia coli, ${ }^{45}$ and molecular interactions in the flower developmental network of Arabidopsis thaliana. ${ }^{46}$

\subsection{Contributions}

There exists a dozen of quantitative models describing various aspects of cell cycle regulation. However, the details of the inhibitory role of p16 in replicative senescence and DNA-damage, as well as the relationship between the p16 mutations and their interaction with protein complexes remain largely unanswered. The present research, to the best of authors' knowledge, describes the most detailed quantitative model of p16-mediated pathway in higher eukaryotes, incorporating the latest experimental observations. We study the quantitative changes in dynamical behavior of the major proteins and protein complexes in response to the mutations of p16 and G1-dysfunction. In this respect, it is noteworthy that our model gives insight into key role of p16 in regulation of replicative senescence and DNA-damage. Throughout our modelling system, we compare the behavior of the major proteins with experimental data, to validate our model and assess in what measure the model reproduce the dynamics of p16-mediated pathway.

\section{Petri nets}

A concept of Petri nets was introduced by Dr. Carl Adam Petri in 1962. An original Petri net sometimes referred to as $\mathrm{P} / \mathrm{T}$-net, is suitable for modelling discrete dynamic systems in which both system's states and transitions between the states are represented in terms of integers. In order to add more modelling power and match modelling tool to system's characteristics, $\mathrm{P} / \mathrm{T}$-net is sometimes expanded with 
time, color, hierarchy, stochasticity, fuzzibility, and other extensions. In a P/T-net with extension, a state is basically composed of discrete and boolean components.

Nevertheless, a $\mathrm{P} / \mathrm{T}$-net with extension is not suitable for modeling the dynamic systems with continuously changing state parameters. Continuous Petri nets were introduced to overcome this drawback. ${ }^{47}$ In a continuous Petri net, real numbers are used to represent continuous change of state parameters. Many dynamic systems are however naturally hybrid employing different structured processes. A state in hybrid systems is a collection of integers, real numbers, boolean values, etc. Hybrid Petri nets are specifically developed to comprise different structured data types, and express explicitly the relationship between continuous and discrete values. ${ }^{48}$

Modelling of biological systems requires often interaction between different structured processes. Biological reactions are natural continuous processes. Reaction rate or reaction speed at which a biological reaction takes place is usually expressed in terms of real numbers. On the other hand, checking for presence/absence of biological phenomenon is a boolean process, while counter-like mechanism is a typical discrete process. In biological reactions, concentration of output component depends on concentrations of input components and the reaction rate. Reaction rates are determined in accordance with the functions that are assigned to biological processes. $\mathrm{HFPN}^{40-43}$ is inherited from hybrid Petri net in which a function is associated with each continuous process.

\section{Model construction}

When modelling biological systems the researchers use terms that are meaningful in biological context. We use terminology adopted in many articles, ${ }^{41-43,49,50}$ and rename place, transition, arc and token respectively as entity, process, connector and quantity in compliance with the biological content. Our model is centered upon gatekeeper role of p16 in regulating p16-mediated pathway. Cascade of biological events induced by each of four possible scenarios regarding p16 mutation and G1dysfunction are described in Fig. 2.

HFPN model of p16-mediated pathway is composed of 28 continuous entities representing mRNAs, proteins, protein complexes, ubiquitin, phosphate, ubiquitinated proteins and phosphorylated proteins; 2 generic entities indicating presence/absence of p16 mutation and G1-dysfunction; 44 continuous processes standing for transcription, translation, nuclear transport, binding, phosphorylation, ubiquitination, mRNA degradation, natural degradation and mutation; 74 process and associate connectors. The model comprises 30 variables $\mathbf{m} \mathbf{1}$ to $\mathbf{m 3 0}$, two of which are introduced to indicate presence/absence status of mutation of p16 ( $\mathbf{m 4}$ ) and G1-dysfunction (m6), and remaining 28 variables are defined to measure the concentrations of biological components. The types and identifiers used in the present model are specified in Fig. 3 We create HFPN model of p16-mediated pathway from biological content information that is briefly discussed in Section $2 .^{1-9,51-58}$ In this model, it is assumed that cyclin D, p16, CDK4 and CDK6 are synthesised in 


\begin{tabular}{|c|c|c|c|}
\hline & \multicolumn{2}{|c|}{ G1-DYSFUNCTION } \\
\hline & & YES & NO \\
\hline \multirow{2}{*}{ 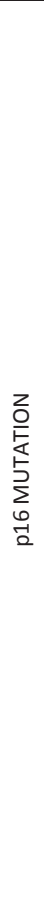 } & $\underset{\nu}{\breve{\nu}}$ & $\begin{array}{l}\text { * Mutated p16 loses its inhibory } \\
\text { function. } \\
\text { * If the reason of dysfunction is } \\
\text { replicative senescence, cells evade } \\
\text { replicative senescence, gaining } \\
\text { immortality, or an extended } \\
\text { replicative lifespan, which leads to } \\
\text { tumor progression in an organism. } \\
\text { * If the reason of dysfunction is DNA } \\
\text { damage, there is no way to arrest cell } \\
\text { cycle at G1 phase and maintain } \\
\text { damaged DNA. Damaged DNA results } \\
\text { in loss of genetic information and } \\
\text { mutations. }\end{array}$ & $\begin{array}{l}\text { * Mutated p16 loses its inhibitory function. } \\
\text { * CycD binds to CDK4/6 resulting in } \\
\text { phosphorylation of Rb, causing successive } \\
\text { cell division until Hayflick limit is reached } \\
\text { or DNA damage arises. } \\
\text { * When the Hayflick limit is reached, cells } \\
\text { evade replicative senescence, gaining } \\
\text { immortality, or an extended replicative } \\
\text { lifespan which leads to tumor progression } \\
\text { in an organism. } \\
\text { * When DNA is damaged there is no way to } \\
\text { arrest cell cycle at G1 phase and maintain } \\
\text { damaged DNA. Damaged DNA results in } \\
\text { loss of genetic information and } \\
\text { mutations. }\end{array}$ \\
\hline & 울 & $\begin{array}{l}\text { Wild-type p16 inhibits binding of } \\
\text { CDK4/6 with CycD by forming a } \\
\text { complex p16CDK4/6, and thereby } \\
\text { preventing Rb phosphory-lation. } \\
\text { * If the reason of dysfunction is } \\
\text { replicative senescence, cells enter into } \\
\text { a state of irreversible growth arrest. } \\
\text { * If the reason of dysfunction is DNA } \\
\text { damage, cell cycle is arrested at G1 } \\
\text { phase until damaged DNA is } \\
\text { maintained. }\end{array}$ & $\begin{array}{l}\text { CycD binds to CDK4/6 resulting in } \\
\text { phosphorylation of Rb, causing successive } \\
\text { cell division until Hayflick limit is reached } \\
\text { in a healthy cell cycle state. }\end{array}$ \\
\hline
\end{tabular}

Fig. 2. Classification of biological events with respect to p16 mutation and G1-dysfunction.

accordance with the central dogma of molecular biology: mRNA transcribed from DNA is then translated into protein. To keep the concentration of related mRNAs at specified level we use associate connectors between mRNA entries and related transcription processes. The abundance of mRNA that no longer used for protein production is destroyed by mRNA degradation. All unnecessary proteins and protein complexes are also discarded by protein degradation. In addition, cyclin D is subject to proteasome-mediated degredation.

Relationship between entities and biological components is illustrated in Table 1. Likewise, correspondence between processes and biological phenomena is detailed in Table 2 and Table 3. Information on connectors including firing styles, firing scripts, and connector types are described in Table 4. Biological phenomenon depends on many parameters including type of substrates, type of culture, environmental factors, etc. It is hard, if not impossible, to determine exact rates based on data coming from biological laboratory experiments. It is uncommon that two identical exper- 
Table 1. Correspondence between biological components and HFPN entities.

\begin{tabular}{|c|c|c|c|c|}
\hline Entity name & Entity type & Variable & Initial value & Value type \\
\hline p16mRNA & Continuous & $\mathrm{m} 1$ & 0 & Double \\
\hline p16(C) & Continuous & $\mathrm{m} 2$ & 0 & Double \\
\hline p16(N) & Continuous & $\mathrm{m} 3$ & 0 & Double \\
\hline Mutation & Generic & $\mathrm{m} 4$ & true/false & Boolean \\
\hline p16mutated & Continuous & $\mathrm{m} 5$ & 0 & Double \\
\hline G1-dysfunction & Generic & $\mathrm{m} 6$ & true/false & Boolean \\
\hline p16_CDK4/6(N) & Continuous & $\mathrm{m} 7$ & 0 & Double \\
\hline p16_CDK4/6(C) & Continuous & $\mathrm{m} 8$ & 0 & Double \\
\hline CDK4mRNA & Continuous & $\mathrm{m} 9$ & 0 & Double \\
\hline $\mathrm{CDK} 4(\mathrm{C})$ & Continuous & $\mathrm{m} 10$ & 0 & Double \\
\hline $\mathrm{CDK} 4(\mathrm{~N})$ & Continuous & $\mathrm{m} 11$ & 0 & Double \\
\hline CDK6mRNA & Continuous & $\mathrm{m} 12$ & 0 & Double \\
\hline CDK6(C) & Continuous & $\mathrm{m} 13$ & 0 & Double \\
\hline CDK6(N) & Continuous & $\mathrm{m} 14$ & 0 & Double \\
\hline CycDmRNA & Continuous & $\mathrm{m} 15$ & 0 & Double \\
\hline $\mathrm{CycD}(\mathrm{C})$ & Continuous & $\mathrm{m} 16$ & 0 & Double \\
\hline $\mathrm{CycD}(\mathrm{N})$ & Continuous & $\mathrm{m} 17$ & 0 & Double \\
\hline CDK4_CDK6 & Continuous & $\mathrm{m} 18$ & 0 & Double \\
\hline CycD_CDK4-6 & Continuous & m19 & 0 & Double \\
\hline Phosphate & Continuous & $\mathrm{m} 20$ & 1 & Double \\
\hline RB_DP_E2F & Continuous & $\mathrm{m} 21$ & 1 & Double \\
\hline $\mathrm{pRB}$ & Continuous & $\mathrm{m} 22$ & 0 & Double \\
\hline DP_E2F & Continuous & $\mathrm{m} 23$ & 0 & Double \\
\hline S_phase_genes & Continuous & $\mathrm{m} 24$ & 0 & Double \\
\hline $\mathrm{pCycD}(\mathrm{N})$ & Continuous & $\mathrm{m} 25$ & 0 & Double \\
\hline $\mathrm{pCycD}(\mathrm{C})$ & Continuous & $\mathrm{m} 26$ & 0 & Double \\
\hline $\mathrm{SCF}$ & Continuous & $\mathrm{m} 27$ & 1 & Double \\
\hline CycD_SCF & Continuous & $\mathrm{m} 28$ & 0 & Double \\
\hline Ubiquitin & Continuous & $\mathrm{m} 29$ & 1 & Double \\
\hline $\mathrm{CycD}[\mathrm{Ub}]$ & Continuous & $\mathrm{m} 30$ & 0 & Double \\
\hline
\end{tabular}

iments lead to identical observations. The results of wetlab experiments regarding rate measurements may sometimes be contradictory. In this work, the rates of biological phenomena are estimated according to their relative rates. We firstly preset rate of transcription to 1 , and then set the rates of remaining biological phenomena by comparing them with the rate of transcription. The process rates adopted in the present work are comparable to those in other works. ${ }^{42,43}$ The process rates are presented in Table 2. 
10 Nimet Ilke Akçay; Rza Bashirov; Şükrü Tüzmen

Table 2. Correspondence between biological phenomena and HFPN processes.

\begin{tabular}{llll}
\hline Biological phenomenon & Process & Process type & Process rate \\
\hline Transcription of p16mRNA & T1 & Continuous & 1 \\
Translation of p16 & T2 & Continuous & $\mathrm{m} 1^{*} 0.1$ \\
Nuclear import of p16 & T3 & Continuous & $\mathrm{m} 2^{*} 0.1$ \\
Mutation of p16 & T4 & Continuous & $\mathrm{m} 2^{*} 0.1$ \\
Binding of p16(N) and CDK4_CDK6 & T5 & Continuous & $\mathrm{m} 3^{*} \mathrm{~m} 18^{*} 0.001$ \\
Nuclear export of p16_CDK4_CDK6 & T6 & Continuous & $\mathrm{m} 7^{*} 0.1$ \\
Transcription of CDK4mRNA & T7 & Continuous & 1 \\
Translation of CDK4 & T8 & Continuous & $\mathrm{m} 9^{*} 0.1$ \\
Nuclear import of CDK4 & T9 & Continuous & $\mathrm{m} 10^{*} 0.1$ \\
Transcription of CDK6mRNA & T10 & Continuous & 1 \\
Translation of CDK6 & T11 & Continuous & $\mathrm{m} 12^{*} 0.1$ \\
Nuclear import of CDK6 & T12 & Continuous & $\mathrm{m} 13^{*} 0.1$ \\
Binding of CDK4 and CDK6 & T13 & Continuous & $\mathrm{m} 11^{*} \mathrm{~m} 14^{*} 0.001$ \\
Transcription of CycDmRNA & T14 & Continuous & 1 \\
Translation of CylinD & T15 & Continuous & $\mathrm{m} 15^{*} 0.1$ \\
Nuclear import of CycD & T16 & Continuous & $\mathrm{m} 16^{*} 0.1$ \\
Binding of CDK4_CDK6 and CycD & T17 & Continuous & $\mathrm{m} 17^{*} \mathrm{~m} 18^{*} 0.001$ \\
Phosphorylation of RB & T18 & Continuous & $\mathrm{m} 19^{*} \mathrm{~m} 20^{*} \mathrm{~m} 21^{*} 0.1$ \\
Transcription of S phase genes & T19 & Continuous & $\mathrm{m} 23^{*} 1$ \\
Nuclear export of pCycD & T20 & Continuous & $\mathrm{m} 25^{*} 0.1$ \\
Binding of pCycD and SCF & T21 & Continuous & $\mathrm{m} 26^{*} \mathrm{~m} 27^{*} 0.001$ \\
Ubiquitination of CycD & T22 & Continuous & $\mathrm{m} 28^{*} \mathrm{~m} 29^{*} 0.01$ \\
Degradation of CycD[Ub] & T23 & Continuous & $\mathrm{m} 30^{*} 0.5$ \\
\hline
\end{tabular}

Table 3. Natural degradations in the HFPN model.

\begin{tabular}{llll}
\hline Biological phenomenon & Process & Process type & Process rate \\
\hline Degradation of mRNAs & $\mathrm{d} 1-\mathrm{d} 4$ & Continuous & $\mathrm{mi}^{*} 0.05$ \\
Degradation of proteins & $\mathrm{d} 5-\mathrm{d} 21$ & Continuous & $\mathrm{mi}^{*} 0.01$ \\
\hline
\end{tabular}

The elements of HFPN model are detailed in Fig. 3, while whole model is demonstrated in Fig. 4. A screen snapshot of HFPN model is illustrated in Fig. 5. The model allows rule-based processing of biological evens in accordance with four scenarios mentioned in Fig. 2. Note that $\mathbf{T} \mathbf{4}$ and $\mathbf{m} \mathbf{4}$ control the status of mutation. Likewise, G1-dysfunction and $\mathbf{m} \mathbf{6}$ check the presence of dysfunction in G1 phase. When p16 is mutated, the rule $\mathbf{m} \mathbf{4}=\mathbf{= 1}$ enables $\mathbf{T} \mathbf{4}$. Occurrence of $\mathbf{T} \mathbf{4}$ arrests p16 in cytoplasm, indicating that p16 is no longer functional as an inhibitor. Otherwise, T3 occurs in accordance with rule $\mathbf{m} \mathbf{4}=\mathbf{=}$, transporting p16 from cytoplasm to 
July 17, $2014 \quad$ 22:42 WSPC/INSTRUCTION FILE jbcb

Validation of signalling pathways: case study of the p16-mediated pathway 11

Table 4. Connectors in the HFPN model.

\begin{tabular}{llll}
\hline Connector & Firing style & Firing script & Connector type \\
\hline c1 & Rule & $\mathrm{m} 4==1$ & Input association \\
c2 & Rule & $\mathrm{m} 6==1$ & Input association \\
c3 & Rule & $\mathrm{m} 4==0$ & Input process \\
c4 & Rule & $(\mathrm{m} 4==0 \& \& \mathrm{~m} 6==0) \|$ & Input process \\
& & $(\mathrm{m} 4==1 \& \& \mathrm{~m} 6==0) \|$ & \\
& & $(\mathrm{m} 4==1 \& \& \mathrm{~m} 6==1)$ & \\
c5-c13 & Threshold & 0 & Input association \\
c14-c49 & Threshold & 0 & Input process \\
c50-c74 & Threshold & 0 & Output process \\
\hline
\end{tabular}

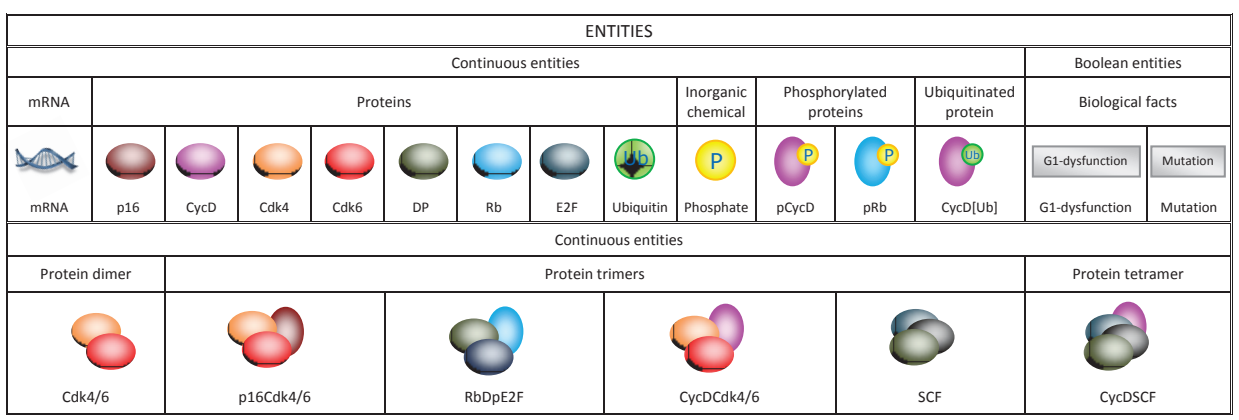
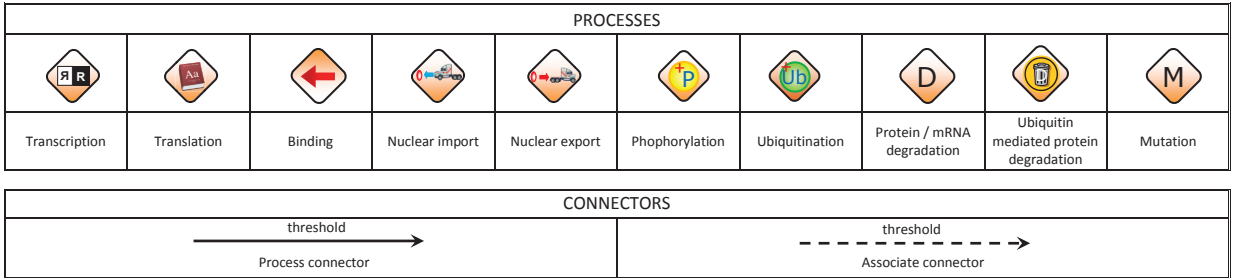

Fig. 3. The elements used in HFPN model.

nucleus. When dysfunction occurs in Gl phase, in appliance with rule $\mathbf{m} \mathbf{6}=\mathbf{= 1}, \mathrm{p} 16$ inhibits formation of CycD-CDK4/6 complex. 


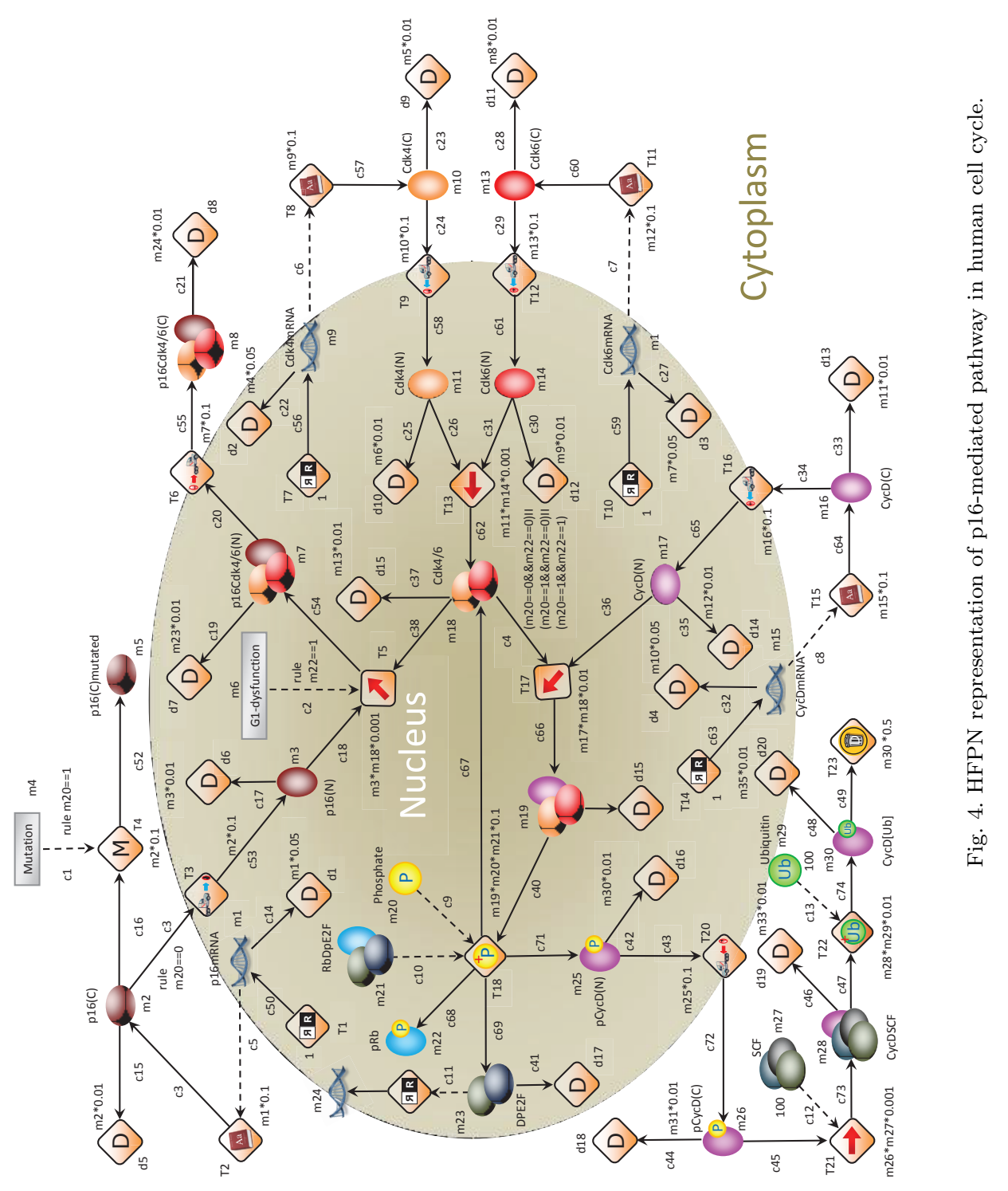


July 17, $2014 \quad$ 22:42 WSPC/INSTRUCTION FILE jbcb

Validation of signalling pathways: case study of the p16-mediated pathway 13

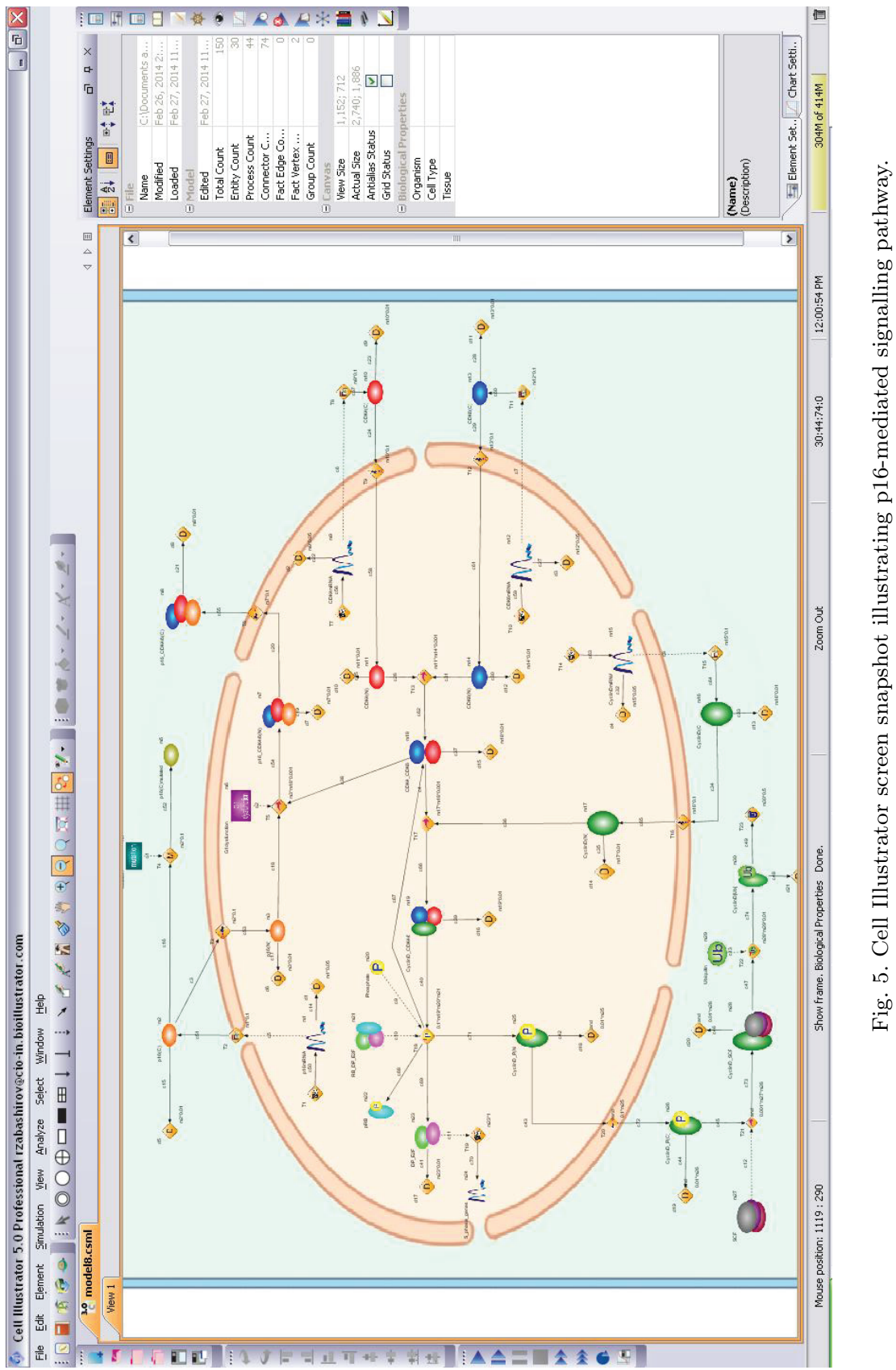


July 17, $2014 \quad$ 22:42 WSPC/INSTRUCTION FILE jbcb
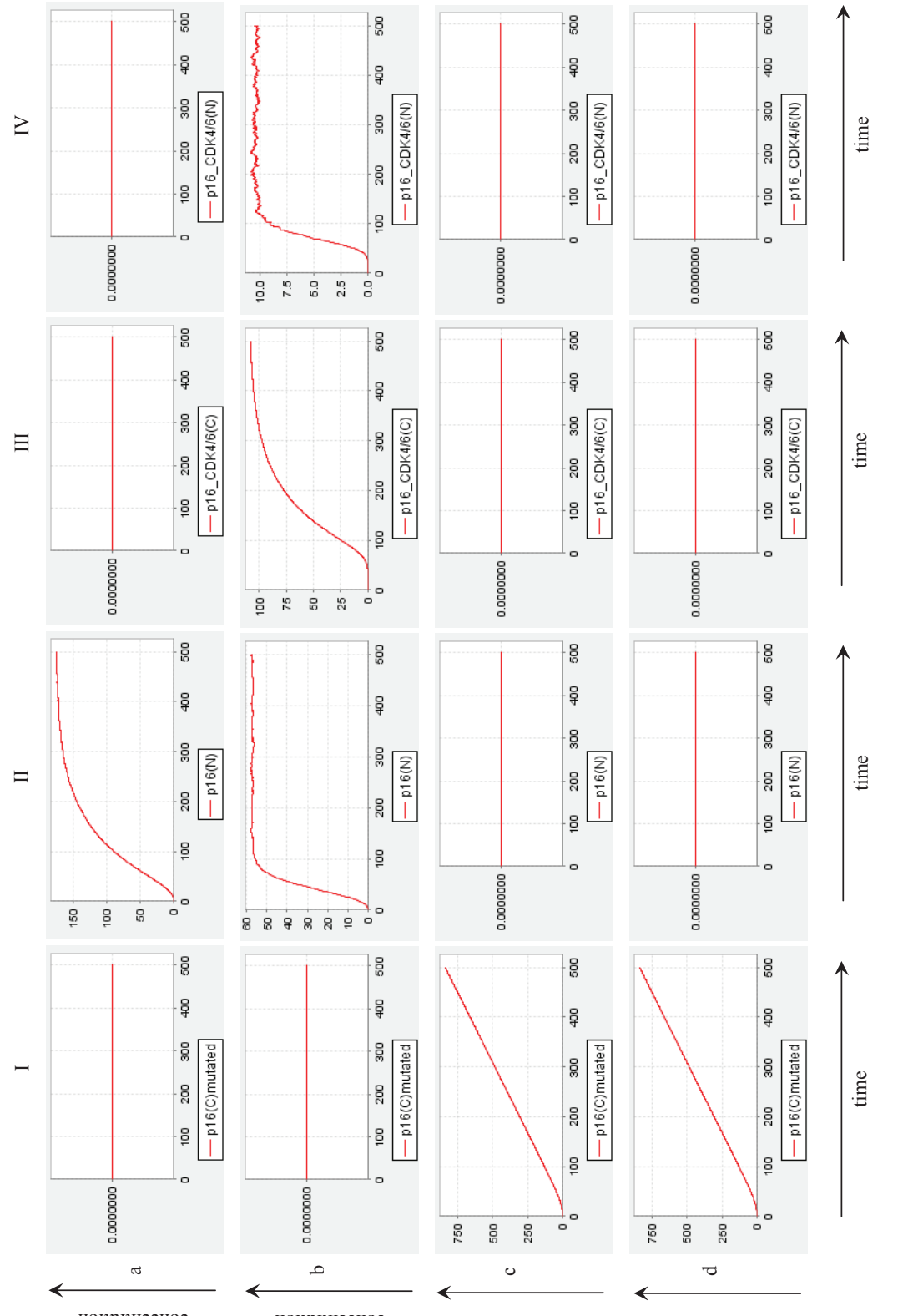

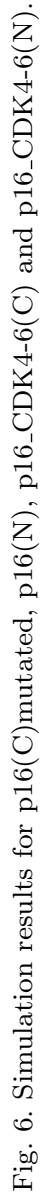
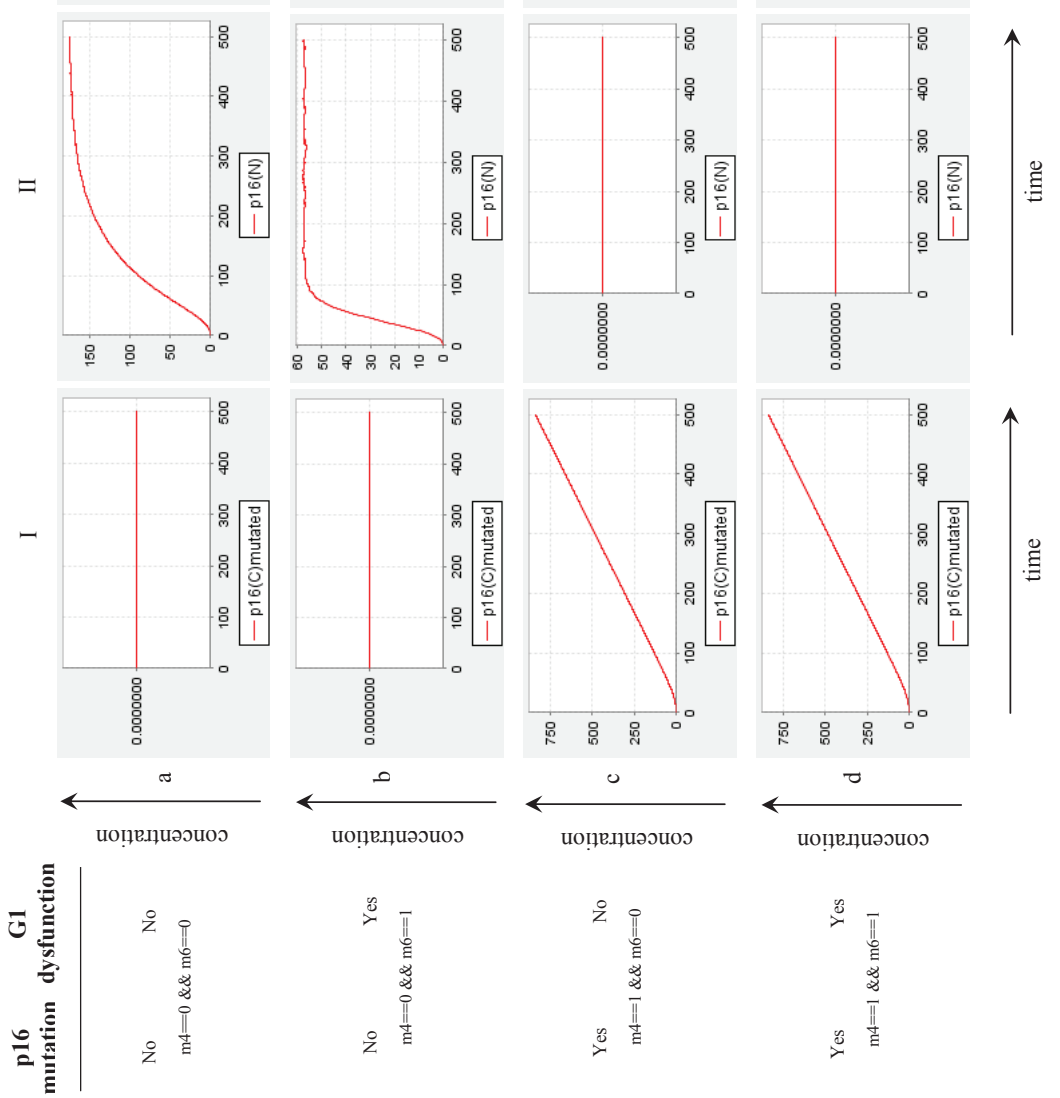
July 17, $2014 \quad 22: 42 \quad$ WSPC/INSTRUCTION FILE jbcb
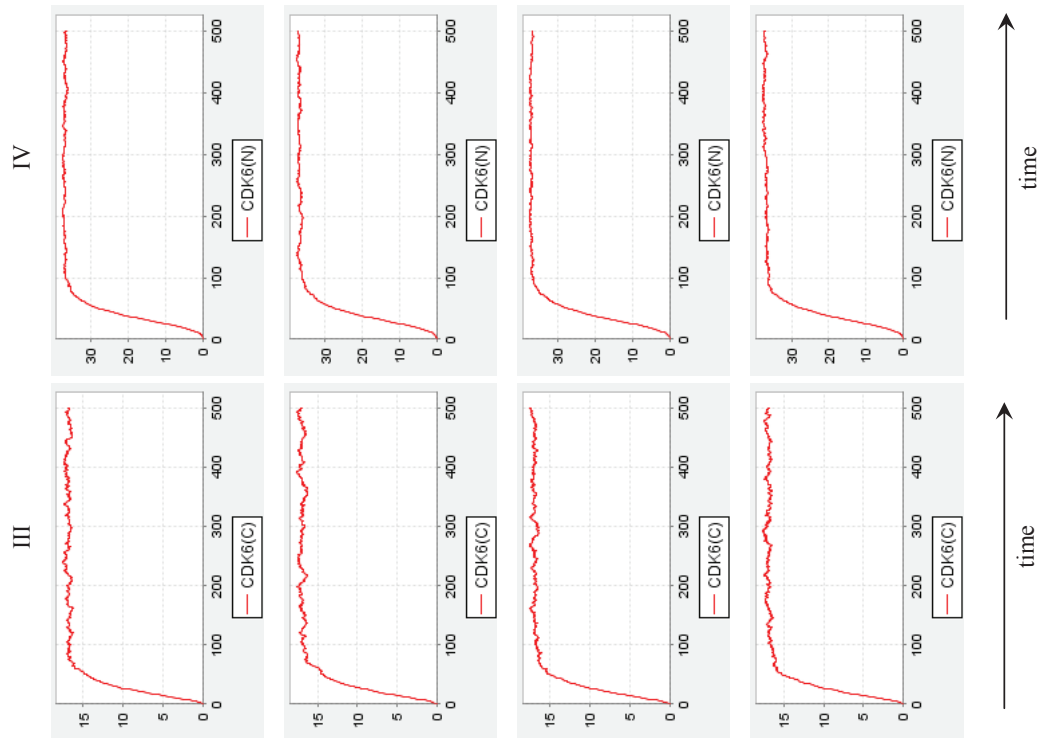

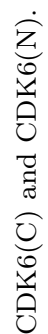
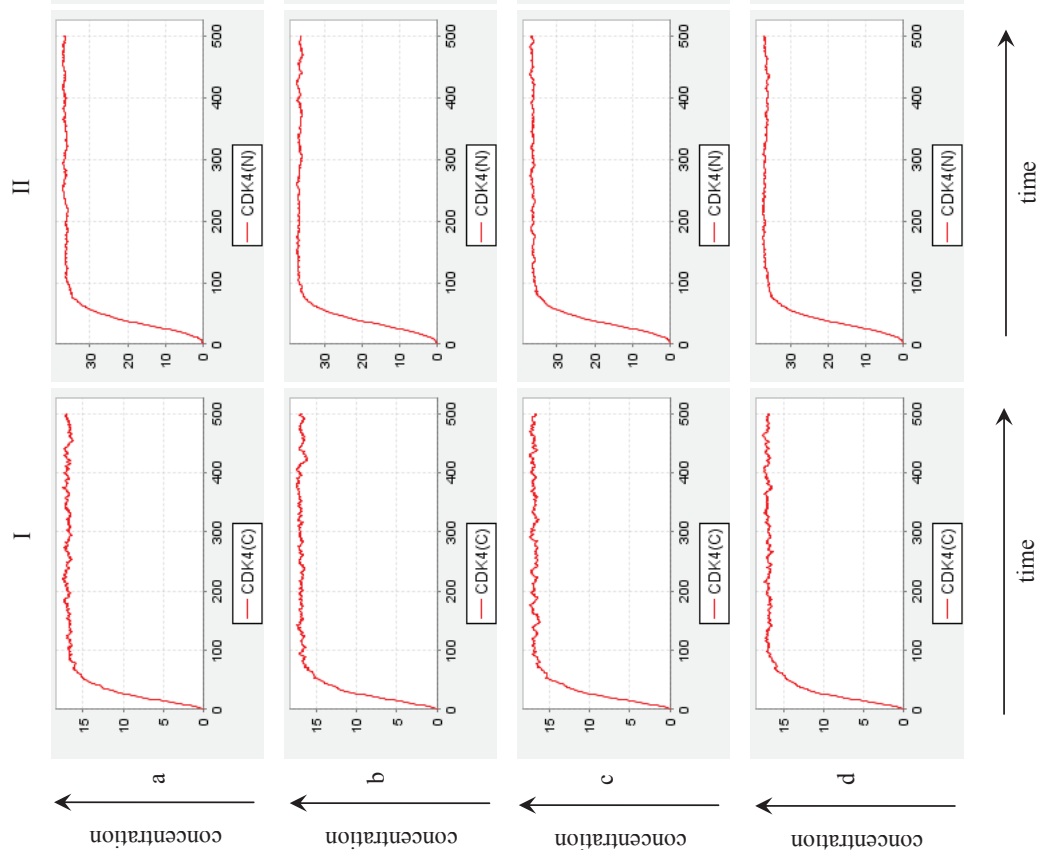

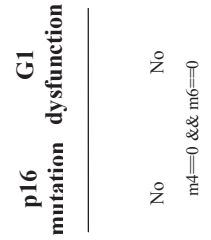
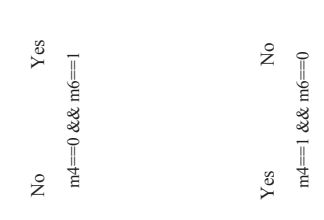

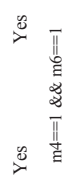


July 17, $2014 \quad$ 22:42 WSPC/INSTRUCTION FILE jbcb
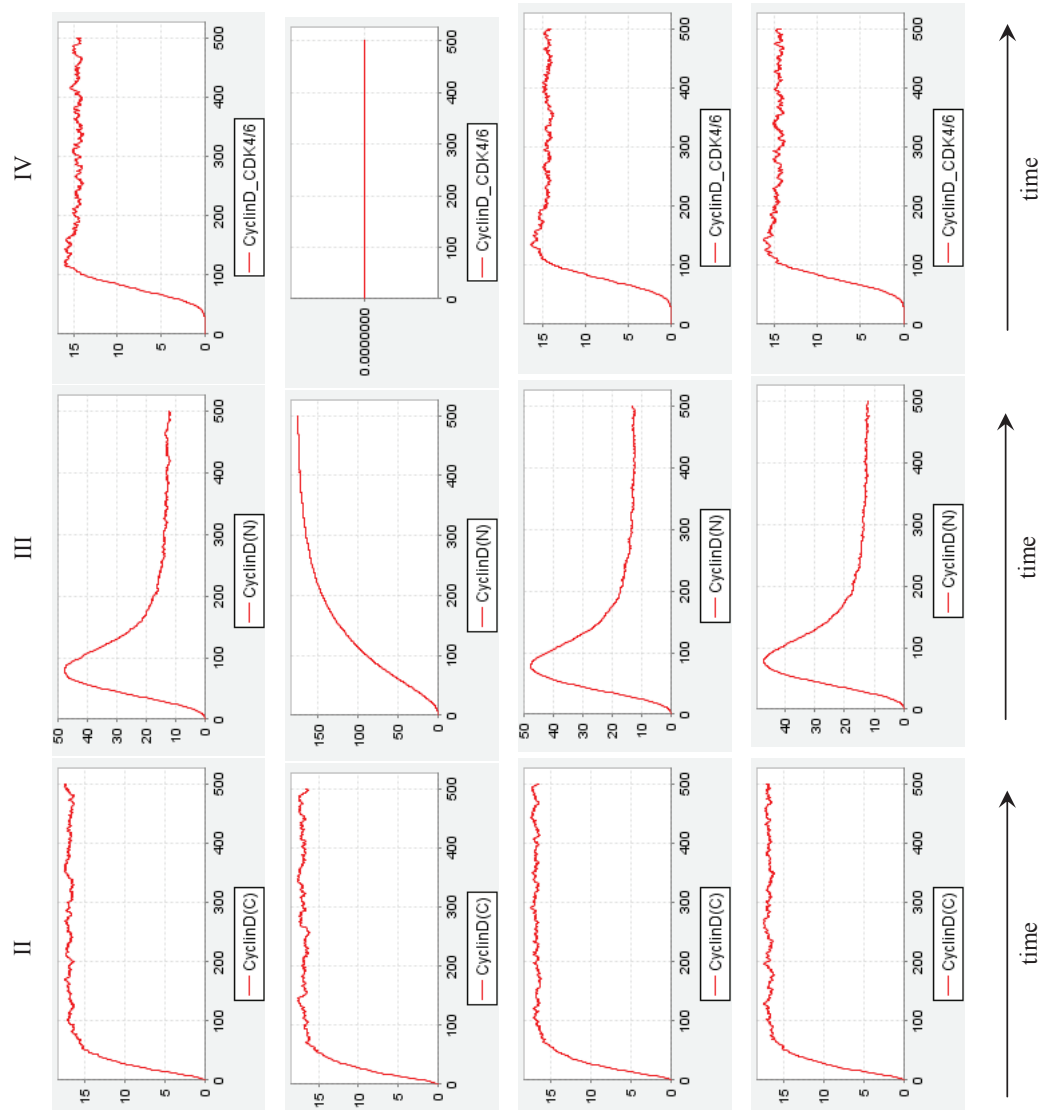

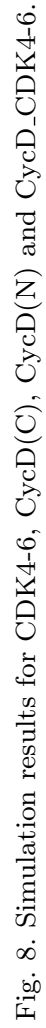
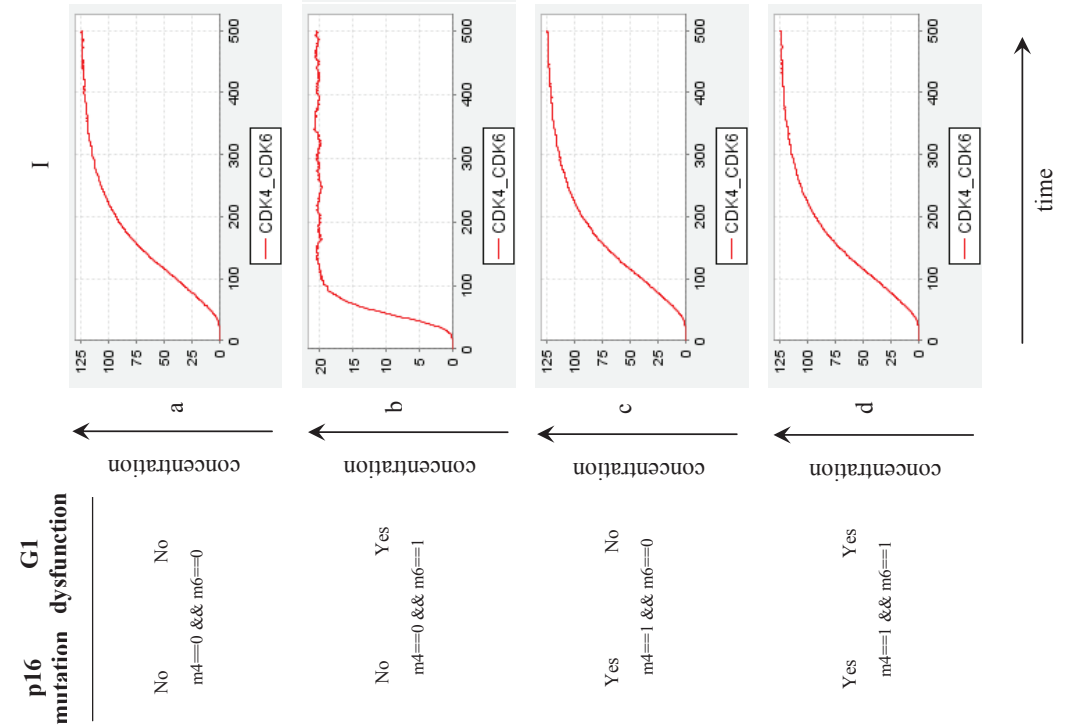


\section{Simulations and Validation}

The concentrations are plotted against time units called Petri time or pt, for short. In order to make simulation results comparable for all components, we performed the simulations at same pt sampling interval and consequently same simulation granularity. Although asymptotic behaviors of measured concentrations were observed within $200 \mathrm{pt}$, for clarity of observations we continued simulating until $500 \mathrm{pt}$. The simulations were conducted in accordance with the following four cases: (a) p16 is active but G1-dysfunction does not occur; (b) p16 is active and G1-dysfunction occurs; (c) p16 is inactivated and G1-dysfunction does not occur; and (d) p16 is inactivated and G1-dysfunction occurs.

Some researchers report on complete disruption of cyclin D by proteasomemediated ubiquitination at the end of G1 phase, ${ }^{59}$ while others claim that unlike cyclins A, B and E, whose levels oscillate during the cell cycle, cyclin D is subsequently expressed throughout cell cycle, and its levels are more constant. ${ }^{60-62}$ The majority of the researchers, on the other hand, suggest that in wild-type cells the cyclin D levels are high during G1 phase in response to growth factors to initiate DNA synthesis, but then it is suppressed to low levels during $\mathrm{S}$ phase to allow for efficient DNA synthesis, and finally it is induced again in G2 phase to support proliferation. ${ }^{63,64}$ There does not exist, however, absolute consensus among researchers regarding exact levels of cyclin D before, during and after the suppression.

Fig. 8-III shows simulation results for concentration behavior of cyclin D in nucleus. As we observed, when p16 is inactivated by the mutations and/or dysfunction is not detected in G1 phase, the concentration of cyclin D within nucleus is induced rapidly so that it reaches the peak level at 50 in approximately $75 \mathrm{pt}$. Then the concentration is reduced rapidly to low levels due to the proteasome-mediated ubiquitination. Asymptotic behavior of cyclin D is clearly observed close to the concentration units of 175 . Then cyclin D enters to the steady constant state. The simulation results in Fig. 8-III- $\{\mathrm{a}, \mathrm{c}, \mathrm{d}\}$ show that the levels of cyclin D are high in G1 phase and it is low in the S phase, as it is observed by some researchers, ${ }^{63,64}$ but it is neither completely disrupted as it is reported by other researchers ${ }^{59}$ nor it is subsequently expressed to keep the concentration at constant level as it is suggested in several papers. ${ }^{60-62}$

When G1-dysfunction occurs, functional p16 inhibits binding of CDK4/6 to cyclin D by forming the p16_CDK4/6 complex, preventing phosphorylation of Rb and consequently ubiquitination of cyclin $\mathrm{D}$. This event might be predicted to result in accumulation of high levels of cyclin D concentration in nucleus. Simulation results illustrated in Fig. 8-III-b are in agreement with this prediction. The cyclin D concentration within sampling interval reaches its maximum level, which is close to 175 units. Furthermore, comparing the concentration levels of the p16_CDK4/6 in nucleus (Fig.6-III-b) with cytoplasmic one (Fig.6-IV-b) one we observe that p16_CDK4/6 is mainly accumulated in cytoplasm rather than in nucleus. This result is rather interesting since to the best of our knowledge, this outcome has not 
been reported in the literature so far. Under assumption that p16 is functional at the absence of G1-dysfunction, cyclin D successfully binds to CDK4/6 resulting in accumulation of functional p16 in nucleus (Fig. 6-II-a). Comparing two cases in Fig. 8-III-b and Fig. 6-II-a, we observe that maximum levels of cyclin D and p16 concentrations in the nucleus are the same, which is close to the level of 175 units.

Inactivation of p16 by the mutations has been reported to be a critical event in tumor progression. Almost 50\% of all human cancers show loss of p16 function. There is evidence that some neoplasms exhibit remarkable amount of p16 concentration in cytoplasm. Study of cytoplasmic accumulation of p16 is indeed a recent event. The mechanisms behind p16 arrest in cytoplasm have not been clarified yet, though there are few hypotheses to explain the accumulation of p16 in cytoplasm. The consequences triggered by the loss of p16 function are discussed in Fig. 2. In the light of previous experimental observations, inactivation of p16 by the mutations, arrests p16 in cytoplasm and that it cannot be transported to the nucleus. Simulation results in Fig. 6-I- $\{\mathrm{c}, \mathrm{d}\}$ reveal that inactivation of p16 is characterized by monotonic stable steady-state of p16 cytoplasmic concentration with approximately linear rate of growth. Close to the end of sampling time mutated p16 in cytoplasm reaches its peak level at 750 . We know that p16 mutations usually arise in the form of promoter methylation, homozygotic deletion and loss of heterozygosity. Impact of mutation types to concentration behavior of p16 needs to be further investigated.

Simulation results for CDK4 and CDK6 in Fig. 7 reveal that levels of CDK proteins in cells vary little throughout the cell cycle, which is in agreement with wet lab results. ${ }^{54}$ The fact that equal amounts of cyclin D (Fig. 8-III-b) and p16 (Fig. 6-II-a) concentrations are available for binding with CDK4/6 coupled with a constant rate of binding reaction might be predicted to result in equal amount of CDK4/6 concentrations left after forming resulting complexes. However, simulation results for CDK4/6 in Fig. 8-I is somewhat surprising - the amount of CDK4/6 concentration remained is as high as 125 in cases (a), (c) and (d), and it is as low as 20 in case (b). The following could be a reasonable explanation for this observation. When DNA-damage or replicative senescence occurs p16 binds to CDK4/6 preventing $\mathrm{Rb}$ phosphorylation. This event consequently arrests cell cycle until damaged DNA is maintained or it remains so continuously if replicative senescence occurs. Dynamic behavior of CDK4/6 for case Fig.8-I-b thus supports this idea as low levels of CDK4/6 concentration remained after forming p16_CDK4/6 is insufficient to initiate $\mathrm{Rb}$ phosphorylation.

\section{Concluding remarks and further work}

This paper describes detailed quantitative model of p16-mediated pathway in higher eukaryotes. Components of this pathway are frequently found to be inactivated, downregulated or overexpressed in human cancer. We perform simulations under assumptions regarding p16 inactivation by the mutations, DNA-damage and replicative senescence. Simulation results show that our model is consistent with most of 
the available experimental observations about p16-mediated pathway. We are able to interpret the simulation results in a meaningful way whenever we fail to find an experimental observation to compare these results with.

The main findings of the present work are summarized below:

(a) In wild-type cells, the cyclin D levels are high during G1 phase to initiate DNA synthesis, but then it is suppressed to low levels during $\mathrm{S}$ phase to enable DNA synthesis (Fig. 8-II-a);

(b) Inactivation of p16 by the mutations, a critical event in tumor progression, results in an increase in its cytoplasmic concentration (Fig. 6-I- $\{\mathrm{c}, \mathrm{d}\}$ );

(c) When p16 is functional and there exists dysfunctionality in G1 phase, then p16_CDK4/6 is mainly accumulated in cytoplasm rather than in nucleus (Fig. 6-III-b, Fig. 6-IV-b);

(d) In wild-type cells, high levels of functional p16 is accumulated in the nucleus (Fig. 6-II-a);

(e) High levels of cyclin D are accumulated in nucleus when p16 is functional and DNA is damaged or replicative senescence occurs (Fig. 8-III-b);

(f) Simulation results for CDK4 and CDK6 reveal that levels of CDK proteins in cells vary little throughout the cell cycle (Fig. 7);

(g) CDK4/6 level is high in all cases (Fig. 8-I- $\{a, c, d\}$ ) except when p16 is functional and DNA-damage or replicative senescence occurs (Fig. 8-I-b). In the latter case CDK4/6 concentration is reduced to low levels, because functional p16 binds to CDK4/6, causing nuclear export of resulting complex.

In concert with experimental approaches, the next phase of our research will focus on developing analogously detailed model for p21-mediated pathway, G1-to$\mathrm{S}$ and G2-to-M checkpoints. All these models can then be coupled to complete big picture of cell cycle in higher eukaryotes as a modular signalling network. The underlying dynamical behavior of these models might have implications in diagnosis, prognosis and treatment of human cancers.

\section{References}

1. Weinert T, Hartwell L, Control of G2 delay by the rad9 gene of Saccharomyces cerevisiae, J Cell Sci Suppl 12:145-148, 1989.

2. Dori-Bachash M, Shema E, et al., Coupled evolution of transcription and mRNA degradation, PLoS Biol 9(7):e1001106, 2011.

3. Hayflick L, The Limited in vitro lifetime of human diploid cell strains, Exp Cell Res 37:614-636, 1965.

4. Stevaux O, Dyson NJ, A revised picture of the E2F transcriptional network and RB function, Curr Opin Cell Biol 14:684-691, 2002.

5. Trimarchi JM, Lees JA, Sibling rivalry in the E2F family, Nat Rev Mol Cell Biol 3:11$20,2002$.

6. Matheu A, Maraver A, et al., Anti-aging activity of the Ink4/Arf locus, Aging Cell 8(2):152-161, 2009.

7. Walkley CR, Orkin SH, RB is dispensable for self-renewal and multilineage differenti- 
20 Nimet Illke Akçay; Rza Bashirov; Şükrü Tüzmen

ation of adult hematopoietic stem cells, Proc Natl Acad Sci USA 103(24):9057-9062, 2006.

8. Baker DJ, Perez-Terzic C, et al., Opposing roles for p16Ink4a and p19Arf in senescence and ageing caused by BubR1 insufficiency, Nat Cell Biol 10(7):825-836, 2008.

9. Nurse PM, Cyclin dependent kinases and cell cycle control (Nobel Lecture), Bioscience rep 22(5-6):487-499, 2002.

10. Brazhnik P, Tyson JJ, Cell cycle control in bacteria and yeast: a case convergent evolutution, Cell Cycle 5:522-529, 2006.

11. Li S, Brazhnik P, et al., A quantitative study of the cell division cycle of Cauloubacter crescentus stalked cells, PLoS Comput Biol 4:e64, 2008.

12. Novak B, Tyson JJ, Numerical analysis of a comprehensive model of M-phase control in Xenopus oocyte extracts and intact embryos, J Cell Sci 106(4):1153-1168, 1993.

13. Pomerening JR, Sontag ED, et al., Building a cell cycle oscillator: hysteresis and bistability in the activation of Cdc2, Nat Cell Biol 5:346-351, 2003.

14. Sha W, Moore J, et al., Hysteresis drives cell-cycle transitions in Xenopus laevis egg extracts, Proc Natl Acad Sci USA 100:975-980, 2003.

15. Sha W, Moore J, et al., Hysteresis drives cell-cycle transitions in Xenopus laevis egg extracts, Proc Natl Acad Sci USA 100:975-980, 2003.

16. Braunewell S, Bornholdt S, Superstability of the yeast cell cycle dynamics: ensuring causality in the presence of biochemical stochasticity, J Theor Biol 245:638-643, 2007.

17. Chen KC, Csikasz-Nagy A, et al., Kinetic analysis of a molecular model of the budding yeast cell cycle, Mol Biol Cell 11:369-391, 2000.

18. Chen KC, Calzone L, et al., Integrative analysis of cell cycle control in budding yeast, Mol Biol Cell 15:3841-3862, 2004.

19. Mura I, Csikasz-Nagy A, Stochastic Petri net extensions of a yeast cell cycle model, $J$ Theor Biol 254:850-860, 2008.

20. Queralt E, Lehane C, et al., Downregulation of PP2A(Cdc55) phosphatase by separase initiates mitotic exit in budding yeast, Cell 125:719-732, 2006.

21. Sriram K, Bernot G, et al., A minimal mathematical model combining several regulatory cycles from the budding yeast cell cycle, IETSyst Biol 1:326-341, 2007.

22. Stelling J, Gilles ED, Mathematical modeling of complex regulatory networks, IEEE Trans Nanobioscience 3:172-179, 2004.

23. Cross FR, Archambault V, et al., Testing a mathematical model for the yeast cell cycle, Mol Biol Cell 13:52-70, 2002.

24. Lygeros J, Koutroumpas K, et al., Stochastic hybrid modeling of DNA replication across a complete genome, Proc Natl Acad Sci USA 105:12295-12300, 2008.

25. Novak B, Tyson JJ, Modeling the control of DNA replication in fission yeast, Proc Natl Acad Sci USA 94:9147-9152, 1997.

26. Csikasz-Nagy A, Kapuy O, et al., Modeling the septation initiation network (SIN) in fission yeast cells, Curr Genet 51:245-255, 2007.

27. Sveiczer A, Csikasz-Nagy A, et al., Modeling the fission yeast cell cycle: quantized cycle times in wee1-cdc25Delta mutant cells, Proc Natl Acad Sci USA 97:7865-7870, 2000.

28. Steuer R, Effects of stochasticity in models of the cell cycle: from quantized cycle times to noise-induced oscillations, J Theor Biol 228:293-301, 2004.

29. Fujita S, Matsui M, et al., Modeling and simulation of fission yeast cell cycle on hybrid functional Petri net, IEICE Trans Fundamentals E-87-A(11):2919-2928, 2004.

30. Calzone L, Thieffry D, et al., Dynamical modeling of syncytial mitotic cycles in Drosophila embryos, Mol Syst Biol 3:131, 2007.

31. Ciliberto A, Tyson JJ, Mathematical model for early development of the sea urchin 
embryo, Bull Math Biol 62:37-59, 2000.

32. Herajy M, Schwarick M, A hybrid Petri net model of the eukaryotic cell cycle, in Heiner M, Höfestaedt R (eds.) Proc. 3rd Inter. Workshop on Biological Processes and Petri nets (BioPPN), Vol.852, CEUR, Hamburg, 25 June, pp 29-43, 2012.

33. Csikasz-Nagy A, Computational systems biology of the cell cycle, Brief Bioinform 10(4):424-434, 2009.

34. FußH, Dubitzky W, et al., Mathematical models of cell cycle regulation, Brief Bioinform 6(2):163-177, 2005.

35. Gerard C, Goldbeter A, Temporal selforganization of the cyclin/Cdk network driving the mammalian cell cycle, Proc. Natl Acad. Sci. USA 106(21):21643-21648, 2009.

36. Swat M, Kel A, et al., Bifurcation analysis of the regulatory modules of the mammalian $G_{1} / S$ transition, Bioinformatics 20(10):1506-1511, 2004.

37. Qu Z, Weiss JN, et al., Regulation of the mammalian cell cycle: a model of the G1-to-S transition, Am J Physiol Cell Physiol 254:344-364, 2013.

38. Szallasi Z, Stelling J, et al., System modeling in cellular biology - From concepts to nuts and bolts, Cambridge, MA, MIT Press, 2006.

39. Chaouiya C, Petri net modelling of biological networks, Brief Bioinform 8:210-219, 2007.

40. Li S, Nagasaki M, et al., Simulation-based model checking approach to cell fate specification during Caenorhabditis elegans vulval development by hybrid functional Petri net with extension, BMC Systems Biology 3(42), 2009.

41. Matsuno H, Tanaka Y, et al., Biopathways representation and simulation on Hybrid Functional Petri Nets, In Silico Biol 3(3):389-404, 2003.

42. Doi A, Fujita S, et al., Constructing biological pathway models with Hybrid Functional Petri Nets, In Silico Biol 4(3):271-291, 2004.

43. Doi A, Nagasaki M, et al., Simulation-based validation of the p53 transcriptional activity with hybrid functional Petri net, In Silico Biol, 6(1-2):1-13, 2006.

44. Assaraf YG, Ifergana I, et al., Computer modelling of antifolaten, inhibition of folate metabolism using hybrid functional petri nets, J Theor Biol 240:637-647, 2006.

45. Castellini A, Franco G, et al., Hybrid functional Petri nets as MP systems, Nat Comput 9(1):61-81, 2010.

46. Kaufmann K, Nagasaki M, et al., Modelling the molecular interactions in the flower developmental network of Arabidopsis thaliana, Annals of Botany 107(9):1545-1556, 2011.

47. David R, Alla H, Continuous Petri nets, Proc. 8th European Workshop on Application and Theory of Petri nets, Zaragosa, Spain, pp 275-294, 1987.

48. Alla H, David R, Continuous and hybrid Petri nets, J Circuits Syst Comp 8(1):159$188,1998$.

49. Çetin N, Bashirov R, Tüzmen Ş, Petri net based modelling and simulation of p16Cdk4/6-Rb pathway, in Heiner M, Balbo G (eds.), Proc. 4th Int. Workshop on Biological Processes and Petri nets (BioPPN), Vol.988, CEUR, Milan, 24-25 June, pp 30-44, 2013.

50. Nagasaki M, Doi A, et al., Genomic object net: A platform for modelling and simulating biopathways, Appl Bioinformatics 2(3):181-184, 2004.

51. Agherbi H, Gaussmann-Wenger H, et al., Polycomb mediated epigenetic silencing and replication timing at the INK4a/ARF locus during senescence PLoS One 4(5):e5622, 2009.

52. Bartkova J, Lukas J, et al., The p16-cyclinD/CDK4-pRb pathway as a functional unit frequently altered in melanoma pathogenesis, Cancer Res 56(23):5475-5483, 1996.

53. Lin DI, Barbash O, et al., Phosphorylation-dependent ubiquitination of cyclin D1 by 
the SCF(FBX4-alphaB crystallin) complex, Mol Cell 24(3):355-366, 2006.

54. Malumbres M, BaRbacid M, Cell cycle, CDKs and cancer: a changing paradigm, Nat Rev Cancer 9(3):153-166, 2009.

55. Murray AW, Recycling the cell cycle: cyclins revisited, Cell 116:221-234, 2004.

56. Sherr CJ, Cancer cell cycle, Science 274:1672-1677, 1996.

57. Vidal A, Koff A, Cell-cycle inhibitors: three families united by a common cause, Gene 247(1-2):1-15, 2000.

58. Weissman AM, Shabek N, et al., The predator becomes the prey: regulating the ubiquitin system by ubiquitylation and degradation, Nat Rev Mol Cell Biol 12(9):605$620,2011$.

59. Moeller SJ, Sheaff RJ, G1 phase: components, conundrums, context, in Kaldis P (ed.) Cell cycleregulation, Springer-Verlag Berlin Heidelberg, 2005.

60. Bird RC, Role of cyclins and cyclin-dependent kinases in G1 phase prpgression, in Boonstra J (ed.), G1 phase progression, Kluwer Academic, New York, pp 40-57, 2003.

61. Boonstra J, Restriction points to the G1 phase to the mammalian cell cycle, in Boonstra J (ed.), G1 phase progression, Kluwer Academic, New York, pp 1-7, 2003.

62. Post SM, Lee E, Detection of kinese and phosphatase activities, Meth Mol Biol bf 241:285-297, 2004.

63. Yang K, Masahiro H, et al., Variations in cyclin D1 levels through the cell cycle proliferative fate of a cell, Cell Division 1(32). doi:10.1186/1747-1028-1-32, 2006.

64. Stacey DW, Three observations that have changed our understanding of cyclin D1 and p27 in cell cycle control, Genes and cancer 12(1):1189-1199, 2010.

\section{Acknowledgments}

We thank Hiroshi Matsuno for help at early stages of this research and for his useful comments on this manuscript.

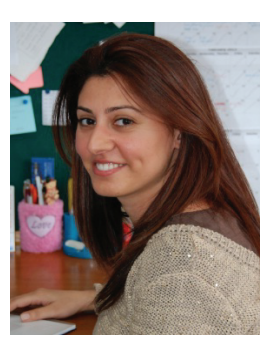

Nimet İlke Akçay received her B.Sc. degree in Mathematics from Izmir University of Economics and M.Sc. degree in Biomathematics from Illinois State University in 2009 and 2011, respectively. She is currently a $\mathrm{PhD}$ Candidate and Research Assistant in Eastern Mediterranean University, North Cyprus. Her research areas include Bioinformatics, Petri Nets, Mathematical Modeling.

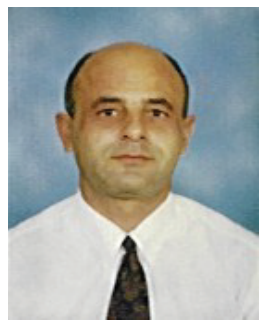

Rza Bashirov received his B.Sc. degree in Applied Mathematics from Baku State University and his Ph.D. degree in Computer Science from Moscow State University in 1982 and 1990, respectively. He is currently Dean of the Faculty of Arts and Sciences and Professor at the Eastern Mediterranean University, North Cyprus. His current areas of research interest include Bioinformatics, Petri Nets and Cryptography. 


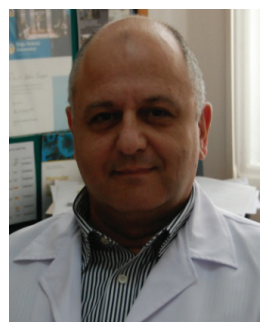

Şükrü Tüzmen received his B.Sc., M.Sc. degrees in Biology and Ph.D. degree in Molecular Biology and Genetics from Bogazici University, Ankara, in 1990, 1992 and 1995, respectively. He is currently Associate Professor at the Eastern Mediterranean University, North Cyprus. He also holds adjunct positions at the Translational Genomics Research Institute, Arizona State University, and the University of Maryland University College. His current areas of research interest include Molecular Basis of Human Diseases, Beta-Thalassemia Mutations, Cloning Models. 